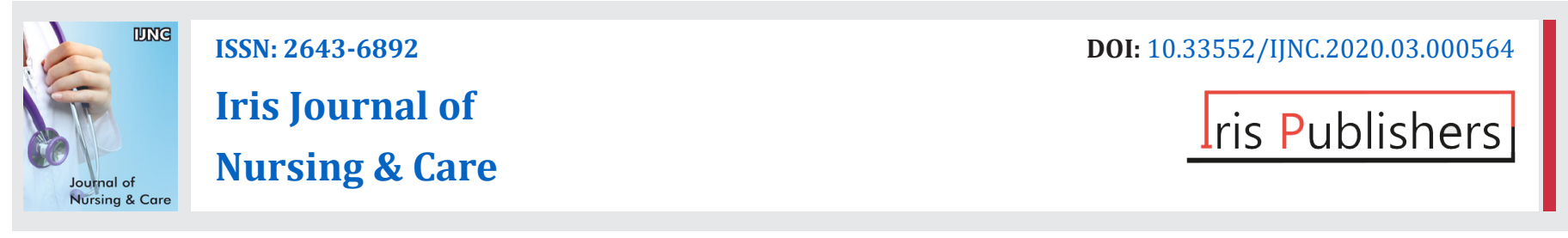

Review Article

Copyright (C) All rights are reserved by Malene Beck

\title{
The Patient's Voice in the Development of Complex Interventions
}

\author{
Malene Beck ${ }^{1 *}$, Charlotte Simonÿ ${ }^{2}$, Janne Brammer Damsgaard ${ }^{3}$, Malene Missel ${ }^{4}$ and Regner Birkelund ${ }^{5}$ \\ ${ }^{1}$ Department of Neurology, Zealand University Hospital, Denmark \\ ${ }^{2}$ Institute of the Regional Health, University of Southern Denmark, Denmark \\ ${ }^{3}$ Department of Public Health, Aarhus University, Denmark \\ ${ }^{4}$ Department of cardiothoracic surgery, Copenhagen University hospital, Denmark
}

${ }^{5}$ Department of Health Services Research, Lillebaelt Hospital, Denmark

*Corresponding author: Malene Beck, Associate Professor, Head of Nursing

Research, Department of Neurology, Zealand University Hospital, Denmark

Received Date: October 22, 2020

Published Date: November 23, 2020

\begin{abstract}
Listening to ill persons and letting their perspectives guide the design and assessment of clinical interventions permits a considerably important illumination of illness diversity, as well as given insight in these people's needs, wishes and values. This paper represents reflections on the creation of knowledge concerning the importance of aesthetics in hospital settings. Applying a phenomenological-hermeneutic methodological approach to qualitative data of patients' experiences is concerned with regards to investigating what being-in-the-world means in specific environmental settings during hospitalization. There are few published studies that describe the meaning of developing and evaluating complex interventions based on qualitative data. This paper illuminates how a phenomenological-hermeneutical approach can be of guidance when developing interventions in nursing practice. In this context, there is a discussion of the value of conducting a Ricoeur-inspired analysis and interpretation.
\end{abstract}

Keywords: Qualitative studies; Patients' experiences; Complex interventions; Paul Ricoeur; Phenomenology-hermeneutics

\section{Let Ill Persons' Stories Breathe in Complex Interventions}

Nursing care has always consisted of actions towards increasing patient well-being during sickness. However, in the twenty-first century, the complexity of clinical practice has increased due to the evaluation of technology, specialized knowledge on diagnoses and enhanced ways of handling the care and treatment of ill people [1]. In a multifaceted nursing care setting, a number of various research methods are required to understand and characterize today's practice. Researchers around the world have been occupied with designing, developing and evaluating new interventions in clinical practice in order to improve treatment for the ill persons.

Traditionally, the golden standard for research in interventional nursing care has been an experimental study design with interventions that compare a treatment, service, actions or other components with a control group [2]. According to [2], the best practice is to develop interventions systematically, using the best available evidence and appropriate theories. This implies using a carefully phased approach, starting with a series of pilot studies 
targeted at each of the key uncertainties in the design, moving on to an exploratory stage and then a definitive evaluation. The results should be disseminated as widely, accurately and persuasively as possible, with further quantitative measurements to assist and monitor the process of implementation [2].

In the book 'Complex interventions in Health. An overview of research' methods the authors present novel reflections and suggest including patients' perspectives when conducting complex interventions in clinical practice [1]. The authors also underline the importance of actions taken by nursing care professionals with the aim of improving the patients' experiences during illness. When they use the term 'intervention', they subsume terms such as 'activities' and 'actions' that are often used to describe the work of nurses or other persons laboring in nursing and social care [1]. They outline just how pervasive the complexity is in almost all nursing care interventions. However, there is a lack of knowledge about how the recipients of a given intervention actually experience nursing care and what is important to them in relation to clinical interventions. Hence, publishing qualitative research findings and highlighting processes within complex interventions have not receive same attention as publishing results of traditional studies relying on a 'golden' stand approach [3].

The thought of involving perspectives of the ill people during illness in order to achieve new knowledge about how it is to be "a patient" has undergone an increased focus in healthcare as well as in healthcare research. As concluded by [4], who investigated what counts as evidence-based practice, an overall acknowledgement of patients' experiences being a part of evidence-based practice has grown. However, when developing and evaluating clinical interventions dialogues between researchers and ill persons are often missing. Therefore, interventions based on dialogues with ill persons need to be enhanced in order to explore the ill persons' needs and wishes during illness. Based on the argument of dialogue being an essential way to gain insight into ill persons' perspectives of what is meaningful during sickness, the aim of this paper is to show how the voices of the ill, through dialogue, can provide important perspectives when conducting complex interventions in clinical practice.

\section{Dialogue as a Way Towards Insight}

The Greek philosopher Socrates (469-399 BC) introduced the idea of being in dialogue. Dialogue, which in Greek means 'through words', is about the intention that is present when people talk together. The importance of identifying what it means to be "a patient "in certain settings or when receiving nursing care while complex interventions are being conducted is essential, because this sheds light on aspects that are significant to ill persons, but are blurred or even hidden from researchers and healthcare professionals [5].

The French philosopher Paul Ricoeur (1913-2005) [6-10] explained why it is important to use dialogue to gain knowledge about human beings. Ricoeur (1991) [9] thoroughly elucidated how dialogue can be considered as a phenomenon that, in particular, allows people to share their experiences of being-in-the-world with each other. Ricoeur (1991) [9] emphasized that our understanding of the world can be broadened through language. Through stories, impressions from life as it is lived can be expressed. Such stories can be interpreted and thus provide new knowledge about how life is experienced. [6] pointed out how language can create community, which is illuminated in following quotation: 'Exteriorization and communicability are one and the same thing for they are nothing other than this elevation of a part of our life into the logos of discourse. There the solitude of life is for a moment, anyway, illuminated by the common light of discourse' (p. 19). Using Ricoeur's hermeneutic phenomenology, we are able to discover more about the world through language than what we have already experienced, perceived and understood. However, to expand and qualify our understanding of ill persons' situations during sickness, it is important in a professional context that we open up new ways of interpreting the world. Based on this point of view, this article argues that entering into dialogue with ill people is imperative in the process of developing practices that seek to change clinical practice to common good.

[11] points out that a recognition of the fundamental questions about what it means to be human during sickness is needed. This is due to the fact that the former efforts of understanding ill persons' life situations during hospitalization have received less attention than, e.g., measurements from blood tests, cardiographs, and stethoscopes [11]. Therefore, [11] argue for a hunt towards the existential questions that ill people might have during illness, since caring science cannot be reduced to what is measurable. Illness is first and foremost a significant experience that we live through, and therefore, according to [11], health professionals must be attentive to what interventions mean to the ill persons in order to align their actions towards encountering human (existential) needs during illness and hospitalization.

\section{The Importance of Addressing Ill Persons' Voices in Qualitative Research}

Qualitative research is a generic term for studies that are conducted on the basis of descriptive data and is recognized as a science of words. If you want to understand the characteristic aspects of what it means to be human, you must be where people live their lives and be aware of the mental aspects of life [12]. However, an awareness of something cannot stand alone; awareness is always an 'awareness of something to someone's and herein lies a close link between phenomenology and hermeneutics. Data generation inspired by a phenomenological-hermeneutical approach helps researchers describe and unfold the experiences of humans (professionals, patients, etc.) [13].

Adopting a phenomenological-hermeneutic perspective does not provide us with a certain method but entails that we partake in 
the understanding that it is important how we as human beings live our lives and how this is experienced [12]. Therefore, investigating nursing practice from a phenomenological-hermeneutic perspective stresses that what is experienced by the ill is an important source of information. If we do not care about ill persons' experiences their life-world in other words- we do not care about them and are therefore practicing inhumane care as expressed by Andreasen (2006a) [12].

In nursing care, the concepts 'phenomenological perspective' and 'patient perspectives' are used in various contexts. However, as Andreasen (2006b) [14], as well as other well-known nursing philosophers e.g., Kari Martinsen (2018) have pointed out, it appears that the meaning of these words is not quite clear being just 'humanistic garnish' and buzz words. Phenomenological approaches mean investigating a given phenomenon to gain insight into its eidetic meaning. Thus, phenomenological research questions provide (new) knowledge of what is often 'taken for granted' (Heidegger 1920) in everyday life. Max van Manen (2018) [15] describes phenomenological research as studies of 'what gives itself' in lived experiences. Conducting studies about ill person's perspectives and paying attention to how it is experienced to be in the world as a person with an illness in a hospital setting, it becomes possible to critically reflect on how clinical development can include important aspects from these individuals' point of view. This substantiates an important point made by Ricoeur; that narration on lived life reveals the experienced meaning [16]. Taking this point into research of complex interventions therefore includes an obvious advantage.

\section{Dialogue is Connected to Conducting Qualitative Research}

Complex clinical interventions underpinned by a qualitative approach are rare. Despite this, such an approach has the potential to illuminate aspects that are meaningful to ill people. Studies within nursing have demonstrated how complex interventions with qualitative methods is meaningful to hospitalized patients [1721]. Ill persons are longing for homeliness and aesthetic elements when hospitalized [18]. Hence, the importance of understanding ill persons' life-world perspectives and translating this understanding into clinical practice needs to be subsequently unfolded. In qualitative research, dialogue with ill persons has provided new knowledge to enrich the already existing literature, because reflections on meanings inherent in stories told by ill persons receiving care are unfolded. Thus, it can be argued that giving a voice to patients during an intervention in clinical practice is important, because its heads light into lived experiences from the hospital environment $[19,21]$. Being in peace and quietness is not always possible for ill persons while being hospitalized $[17,18]$. Therefore, studies have focused on improving specific environmental settings in hospitals with focus on the aesthetics [19]. Performing a complex intervention inspired by the guidelines within the MRC framework
$[2,22]$, underpinning a qualitative approach is likely to emphasize how a clinical environment can be developed with respect to the patients that are admitted to hospitals during their course of illness [19-21]investigating the ill person's perspectives on the hospital environment through a dialogue, as a part of an intervention, revealed that individuals were longing for homeliness, because they experienced being in a chaotic setting comparable to a railway station [15-18]. Combined with implementation proposal Prodger (2003) and suggested politics (Hospital Caterers Association (HCA) 2004) from the literature, an environment-changing intervention can be designed [19]. Accordingly, increased focus on aesthetic elements, that is anticipated to create a sense of homeliness, can become key aspects of clinical interventions [20,21].

The meaningfulness and quality of such patient-focused interventions can be appraised by interviewing the ill hospitalized persons about their experiences of the 'new' environment [19]. According to Moore et al. (2015) [23], process evaluation is an essential part of designing interventions; hence, it can be used to assess the fidelity and quality of the implementation. Qualitative approaches is well-suited to helping shed light on the pathways through which the intervention generated its impacts, i.e., why it was successful or not, how the intervention worked, and how it could be optimized [5].

\section{The Necessity of Interpreting Patient's Experiences}

As stated by Crowther et al. (2017) [24] interpretation is a key aspect when crafting stories within the phenomenologicalhermeneutic tradition. Hence, understanding relies on a reflexive engagement within horizons of understanding and interpretation [25]. Ricoeur (1988) [10] argued that human existence embodies thoughts, experiences, feelings and actions that can be recounted by the use of language. He ascribed great significance to narratives, as they allow an interpretation of human existence. In this line of view, ill persons' lives are told through narratives. Accordingly, ill persons' narratives gathered by interviews and transcribed into text can be considered as a work of reflecting how it is to be in the world as an ill person in a particular situation.

Ricoeurs philosophy of narratives and interpretation can also guide the interpretation [26], (Blinded for review). In three phases -naïve reading, structural analysis and critical interpretation and discussion- a dialectical movement from an initial "naïve" understanding towards a "sophisticated" understanding is permitted [7,27]. The interpretation constitutes new knowledge that may be the source of reflections in the development of interventions, because interviews, the interpretation of them, provides insight of how an intervention to ill people are meaningful.

\section{Reflections on Interventions Guided by Qualitative Approaches}

Ill persons' perspectives are important when designing, developing and evaluating interventions [20]. Philosopher Uffe 
Juul Jensen (2013) [28] argues that in dealing with ill people, it is important to adopt a "patient's point of view" to put the expert judgements into perspective and contribute to a wider and deeper understanding. By acknowledging ill persons' perspectives, we can enhance the possibilities of moving in a sustainable direction when developing clinical practice. Moreover, Jensen also argues that applying a "patient perspective" to diagnoses, care and treatment contributes to counteracting the individual's suffering of being lost in a busy and noisy hospital ward with professionals focused on identifying and removing the disease (ibid.).

Therefore, the "patient perspective" is not a special way of handling or relating to the ill persons, but rather, a way of understanding their life situations [25]. From this angle, it is an art or practice that unfolds in a partnership between nursing care professionals and ill persons, aiming to ease suffering and thus promoting nursing (ibid.). In this sense, the ill persons can be seen as 'experts' in the role of being ill. Thus, what is meaningful to ill people must be interpreted in order to understand important aspects of "patient perspectives" on living with a disease. Since multiple aspects of nursing will persistently have blind spots, we can anticipate having a continuous need for knowledge about how the 'experts in being ill' respond to the given nursing services. Acknowledging ill persons' experiences can help us create interventions that are more meaningful, not only for the individual but also for the professionals providing nursing care.

As stated by Richards and Hallberg (2015) [1], the priorities of academic researchers and clinical specialists are often different from the concerns of ill persons. What is important to these ill people determines the meaning of interventions; hence, the ill person's point of view validates the relevance of the interventions in clinical practice. Developing knowledge for practice is an ongoing process, and the problem or question in focus needs to be studied from several perspectives before entering the stage where a complex intervention can be considered.

As pointed out in the beginning, Craig, etal. (2008) [2] underlined that best practice is to develop interventions systematically, using the best available evidence and appropriate theories. We argue that the ill person's perspective holds a significance in itself. For example, essential aspects of hospital mealtimes has been described and documented by conducting an intervention guided by the ill persons' voices [16-20]. If only the quantitative research questions had been prioritized, then the humane aspect of interventional studies had been lost, which would have been crucial in relation to the individual's ability to create an appetite during hospitalization $[18,20]$. Focusing primarily on measuring food intake or counting calories during the intervention, the relationship between appetite and feeling safe and comfortable during mealtimes would never have shown its phenomenological face [29-31]. Therefore, it is crucial that research based on phenomenological-hermeneutic approaches be considered as a new and uplifting perspective in the ongoing discussion about whether to use quantitative or qualitative research methods. Thus, listening to the ill persons' voices during the development of complex interventions illuminate existential issues or phenomena's, as well as ill persons' values, experiences and situation during sickness.

\section{Acknowledgement}

None.

\section{Conflict of Interest}

Author declare no conflict of interest.

\section{References}

1. Richards D, Hallberg I (2015) Complex interventions in Health. An overview of research methods. Routledge. UK.

2. Craig P, Dieppe P, Macintyre S, Mitchie S, Nazareth I, et al. (2008) Developing and evaluating complex interventions: The new medical research council guidance. BMJ: British Medical Journal (International Edition) 337: a1655.

3. Dahlberg K (2006) The Publication of Qualitative Research Findings. Qualitative Health Research 16(3): 444-446.

4. Rycroft Malone J, Seers K, Titchen A, Harvey G, Kitson A, et al. (2004) What counts as evidence in evidence-based practice? J Adv Nurs 47(1): 81-90.

5. Ludvigsen MS, Meyer G, Hall E, Fegran L, Aagaard H, et al. (2013) Development of clinically meaningful complex interventions - the contribution of qualitative research. Pflege 26(3): 207-214.

6. Ricouer P (1973) Filosofiens Kilder. (Sources of Philosophy). Copenhagen Denmark: Vintens Forlag.

7. Ricoeur P (1976) Interpretation Theory. Discource and the Surplus of Meaning. Texas: TCU Press, USA.

8. Ricoeur P (1984) Time and Narrative. The University of Chicago Press, Chicago and London.

9. Ricouer P (1991) Life in quest of narratives. In: Wood D (Eds.), On Paul Ricoeur: narrative and interpretation. Routledge, New York.

10. Ricoeur P (1998) Hermeneutics and the Human Sciences. $\left(2^{\text {nd }}\right.$ edn.) Cambridge University Press, Cambridge, UK.

11. Aho K (2018) Existential medicine. Esseys on health and Illness. Rowman \& Littlefiels International Ltd, Maryland, USA.

12. Andreasen TE (2006a) Fænomenologi og videnskab. del 1. (Phenomenology and Science. Part 1). Tidsskrift for Sygeplejeforskning 22(2): 28-36.

13. Schiemer B (2013) To the things themselves: About hermeneutic phenomenology. In Phenomenology, Theories and Methods Hans Reitzels Forlag, Denmark.

14. Andreasen TE (2006b) Fænomenologi og videnskab. del 2. (Phenomenology and Science. Part 2). Tidsskrift for Sygeplejeforskning, 22(3): 17-24.

15. Van Manen M (1997) Researching lived experience: human science for an action sensitive pedagogy. ( $2^{\text {nd }}$ edn.) London, Ont.: Althouse Press.

16. Beck M, Martinsen B, Poulsen I, Birkelund R (2016) Mealtimes in the neurological ward. A phenomelogical-hermeneutic study. J Clin Nurs 25(11-12): 1614-1623

17. Beck M, Poulsen I, Martinsen B, Birkelund R (2017a) Longing for homeliness: Exploring mealtime experiences of patients suffering from a neurological disease. Scand J Caring Sci 32(1): 317-325.

18. Beck M, Birkelund R, Poulsen I, Martinsen B (2017b) Supporting existential care with Protected Mealtimes: Patients' experiences of a mealtime intervention in a neurological ward. J Adv Nurs 73(8): 19471957. 
19. Beck M, Martinsen B, Birkelund R, Poulsen I (2017c) Raizing a beautifu swan. a phenomenological-hermeneutic interpretation of health professionals' experiences of participating in a mealtime intervention inspired by Protected Mealtimes. Int J Qual Stud Health \& Well-being 12(1): 136-146.

20. Beck M, Birkelund R, Poulsen I, Martinsen B (2020) The meaning of hospital meals: An asylum for patients in a vulnerable situation. Journal of Clinical Nursing.

21. Craig P, Dieppe P, Macintyre S, Michie S, Nazareth I, et al. (2008a) Developing and evaluating complex interventions: New guidance. BMJ 337: a1655.

22. Moore G, Graham A (2015) Process evaluation of complex interventions: Medical Research Council guidance. BMJ 350: h1258.

23. Crowther S, Ironside P, Spence D, smythe L (2017) Crafting Stories in Hermeneutic Phenomenology Research: A Methodological Device. Qual Health Res 27(6): 826-835.

24. Spence DG (2017) Supervising for Robust Hermeneutic Phenomenology: Reflexive Engagement Within Horizons of Understanding. Qual Health Res 27(6): 836-842.

25. Ricoeur P (1988) Time and narrative. The University of Chicago Press, Chicago, London.
26. Dreyer PS, Pedersen BD (2009) Distanciation in Ricoeur's theory of interpretation: narrations in a study of life experiences of living with chronic illness and home mechanical ventilation. Nurs Inq 16(1): 64-73.

27. Missel M, Birkelund R (2019) Ricoeur's narrative philosophy: A source of inspiration in critical hermeneutic health research. Nursing Philosophy.

28. Jensen UJ (2013) Patientperspektivet i en sundhedspraksis under forandring. (Patient perspectives in a changed health care system) In: Martinsen B, Norlyk A \& P. Dreyer (Eds.), Patientperspektivet. En kilde til viden (Patient perspective. A source for knowledge). Latvia: Munksgaard. Pp. 17-30.

29. Pedersen BD (1999) Sygeplejepraksis: sprog \& erkendelse. (Nursing practice: Language and cognition). Århus: University of Aarhus.

30. Simonÿ C, K Specht, IC Andersen Kirsten, Kjær Johansen, Charlotte Nielsen, et al. (2018) A Ricoeur-Inspired Approach to Interpret Participant Observations and Interviews. Glob Qual Nurs Res 5: 233339361880739.

31. Thorgård K. Patientperspektivets epistemologi (The epistemology of patient perspectives). In: Martinsen B, Norlyk A, \& P. Dreyer (Eds.), Patientperspektivet. En kilde til viden (Patient perspective. A source for knowledge), Latvia: Munksgaard, Pp. 17-30. 